\title{
Percepção das mulheres homoafetivas frente a assistência de enfermagem na saúde da mulher
}

\author{
Ilara Parente Pinheiro Teodoro ${ }^{1}$; Nágila Kelly Sidrone Felipe ${ }^{2}$,
} Livia Parente Pinheiro Teodoro ${ }^{3}$

\begin{abstract}
Resumo: Comprometido com a filosofia de saúde enquanto direito e preocupado em garantir à mulher assistência integral, o Sistema Único de Saúde enfatizou a preocupação com seu corpo de forma integral, criando o Programa de Assistência Integral à Saúde da Mulher, porém desde sua implantação foram privilegiadas mulheres heterossexuais, com enfoque particular na saúde reprodutiva. Tendo assim como conseqüência um provável impacto negativo na qualidade da assistência, especialmente na atenção a saúde de mulheres homoafetivas, onde deve ser considerada a relevância da abordagem de suas sexualidades, para que assim aconteça uma orientação e uma educação correta. Com esse estudo objetivou-se conhecer as possíveis barreiras enfrentadas pelas mulheres homoafetivas na assistência de enfermagem na unidade de saúde. Trata-se de um estudo de caráter descritivo com uma abordagem qualitativa, realizado na Associação de Homossexuais de Iguatu - Ceará. A pesquisa cumpriu os requisitos da Resolução No . 196/96, do Conselho Nacional de Saúde/Ministério da Saúde. A amostra compôs-se de 12 sujeitos utilizando uma entrevista semi-estruturada, onde ocorreu no mês de maio de 2011. Os dados foram analisados mediante a técnica de análise de conteúdo e em seguida organizados em categorias com base nos objetivos do estudo. Mediante entrevista verificou-se que prevaleceu à faixa etária de 19 á 22 anos de idade, a maioria com ensino médio completo, e uma renda referente de 2 (dois) salários mínimos, além de estarem distribuías em profissões diversas. Observou-se que a maioria nunca procurou o atendimento. Acreditam que os enfermeiros ainda não estão preparados humanamente para lidar com a homoafetividade feminina e que a educação em saúde não vem sendo trabalhada de forma correta, pois visa à mulher como ser heterossexual. Da mesma forma, relatam também que não existe no conhecimento das mulheres nenhuma atividade realizada para o grupo em questão. Por fim, as mesmas sugeriram que fossem realizados mais treinamentos específicos para os profissionais saberem lidar melhor com o grupo em estudo durante a assistência, para assim melhorar a prevenção de doenças e promoção da saúde dessas mulheres focando principalmente no aspecto da homoafetividade. Conhecer a opção sexual individual do paciente se torna de importância absoluta diante da assistência fazendo de suma necessidade a indagação da mesma para que assim seja feito o atendimento de forma individual e correta, tentando tornar a assistência eficaz e derrubando de uma só vez a homofobia em direção paciente/profissional ou profissional/paciente.
\end{abstract}

Palavras-Chaves: Saúde da Mulher, Mulheres Homoafetivas, Assistência a Saúde.

\section{Perception of Women Homoaffective in facing the Nursing Care in Women's Health}

\begin{abstract}
Committed to the philosophy of health as a right and concerned about ensuring full assistance to women, the Unified Health System emphasized the concern with your body fully, creating the Program for Integral Assistance to Women's Health, but since its implementation were privileged women heterosexual, with particular focus on reproductive health. Having as a likely consequence negative impact on quality of care, especially in the health care of women homoaffective, which should be considered the relevance of their sexualities approach, so that happens a correct guidance and education. With this study aimed to know the possible barriers faced by women in homoaffective nursing care in the health unit. This is a descriptive study with a qualitative approach, performed at the Association of Homosexuals of Iguatu - Ceará. The research complied with the requirements of Resolution No.. 196/96, of the National Board of Health / Ministry of Health. The sample consisted of 12 subjects using a semi-structured interview, which took place in May 2011. Data were

\footnotetext{
${ }^{1}$ Enfermeira graduada pela Universidade Regional do Cariri - URCA, Especialista em Saúde da Família pela Universidade Regional do Cariri - URCA, Docente da Universidade Regional do Cariri - URCA, Campus Iguatu. E-mail: ilaraparente @ yahoo.com.br;

${ }^{2}$ Enfermeira graduada pela Universidade Regional do Cariri - URCA,Campus Iguatu. E-mail: nagilla sidrone@ hotmail.com;

${ }^{3}$ Enfermeira graduada pela Universidade Regional do Cariri - URCA, Especialista em Saúde da Família pela Universidade Regional do Cariri - URCA, Docente da Universidade Regional do Cariri - URCA, Campus Iguatu. E-mail: liviappt @ yahoohotmail.com;
} 
analyzed using the technique of content analysis and then organized into categories based on the goals of the study. Through interviews it was found that prevailed in the age group of 19 to 22 years old, most had completed high school, and a rent for two (2) minimum salaries, in addition to being distributed in various professions. It was observed that most never sought care. Believe nurses are still not prepared to deal humanly with female homoaffectivity and health education has not worked correctly since it refers to the woman as being heterosexual. In the same manner, also report that does not exist in women's knowledge no activity performed for the group in question. Finally, they suggested that more specific trainings were conducted for the professionals know best deal with the study group during the tour, and thus improve disease prevention and health promotion of these women mainly focusing on the aspect of homoaffectivity. Know the sexual orientation of the individual patient becomes of absolute importance on the need of great care making the question the same so that the care of individual and correctly done, trying to make effective assistance and knocking down at once homophobia in toward patient / or professional / patient.

Key-Words: Women's Health, Women Homoaffective,Health Care

\section{Introdução}

As mulheres antes das profundas mudanças societárias das últimas décadas eram vistas somente como submissas aos homens, obrigatória a exercer o papel de reprodutoras, mãe responsável pela educação e criação dos filhos e tendo como obrigação os serviços domésticos, sendo impossibilitadas dos seus direitos diante á sociedade. Assim com o passar do tempo elas vem criando o seu próprio espaço na sociedade tendo direitos de escolhas assim como os homens, igualando os direitos e deveres diante ambos.

Através das lutas do movimento feminista aliadas à profissionais da saúde em 1983 o Ministério da Saúde através da Divisão Nacional de Saúde Materno Infantil (DINSAMI) elaborou o Programa de Assistência Integral à Saúde da Mulher, com o objetivo de reduzir a mortalidade da mulher e da criança (PAISMC). Comprometido com a filosofia de saúde enquanto direito e preocupado em garantir à mulher assistência integral, enfatizou a preocupação com seu corpo de forma integral, e não apenas como órgãos isolados, a serem tratados por diferentes especialistas, assim em 1991 houve a separação, criando o Programa da Assistência Integral à Saúde da Criança (PAISC) e o Programa de Assistência Integral à Saúde da Mulher (PAISM) (BRASIL, 2004a).

As demandas específicas, quanto às mulheres homoafetivas, ressentem-se de acolhimento face aos preconceitos sexuais, porém nos dias atuais a sociedade começa a compreender que a homoafetividade não é boa nem má, mas é uma condição que esteve sempre presente em toda a história da humanidade. O movimento homoafetivo vem conquistando através dos tempos inúmeras vitórias na garantia de direitos, porém podemos observar que os valores reivindicados por eles são muitos e as conquistas apesar de lenta já começam a ocorrer, como foi o caso das leis anti-homofobia e a união civil entre homoafetivos. 
Porém os programas de assistência à saúde da mulher continuam privilegiando pessoas heterossexuais, com enfoque particular na saúde reprodutiva. Desse modo, elas enfrentam inúmeras barreiras para revelar sua orientação sexual nos serviços de saúde, tendo como conseqüência um provável impacto negativo na qualidade da assistência tornando fundamental um vínculo direto entre profissional-usuário, especialmente na atenção a saúde da mulher, onde deve ser considerada a relevância da abordagem da sexualidade.

O profissional normalmente nada pergunta sobre a vida sexual dessas mulheres, assim, para não se exporem, elas aceitam a situação sem questionar, porém é importante enfatizar que elas não estão livres das infecções e nem das doenças sexualmente transmissíveis (DST) apesar de que de acordo com Araújo et al. (2006) elas estão situadas a categorias de baixo risco frente às DSTs e infecções. Daí a importância de um trabalho educativo e de promoção da saúde dessas mulheres.

Diante deste fato, surgiram inúmeras indagações, tais como: Quais as possíveis barreiras enfrentadas pelas mulheres homoafetivas na assistência da unidade de saúde? Existem dificuldades enfrentadas pelas mulheres homoafetivas na assistência de enfermagem na saúde? Essas mulheres homoafetivas participam de alguma atividade educativa? Quais as sugestões que as mulheres homoafetivas tem para melhoria da assistência nas unidades de saúde?

Em meio ás indagações supracitadas o desenvolvimento da pesquisa tem o propósito de realizar um estudo que permite investigar as possíveis barreiras enfrentadas pelas mulheres homoafetivas na assistência de enfermagem. Além de servir de fonte bibliográfica para outras pesquisas, chamar á atenção dos enfermeiros na melhoria da assistência às mulheres homoafetivas, para que durante as assistências sejam feitas indagações que possibilitem serem trabalhadas diversas questões que possam influenciar na promoção a saúde.

\section{Trajeto Metodológico}

Trata-se de uma pesquisa descritiva-exploratória com abordagem qualitativa. O lócus de estudo foi na Associação de Homossexuais de Iguatu (AHI), localizada no município de Iguatu, na Região Sudoeste do Ceará. Esta, compõem-se por participantes homens e mulheres homoafetivos. A AHI tem como principal objetivo a realização de palestras educativas e conversas com familiares de homossexuais que tem dificuldades de aceitação da opção sexual diferenciada.

A população do estudo foi constituída por 12 mulheres homoafetivas que residem na cidade de Iguatu-ce. A coleta foi realizada no mês de maio de 2011, sendo utilizado como instrumento, um roteiro de entrevista semi-estruturada. 
Para a análise dos dados, foi realizado à ordenação das falas, após a transcrição integral das gravações e da leitura do material empírico. A seguir, foram selecionadas partes do material, buscando-se as idéias relevantes que constituem as unidades de significado. A técnica de análise de conteúdo foi utilizada a pré-análise, a exploração do material e a análise e interpretação dos dados, de acordo com o método de Bardin (2008).

A pesquisa em questão cumpriu os requisitos da Resolução No. 196/96, do Conselho Nacional de Saúde/Ministério da Saúde (CNS/MS), que trata das diretrizes e normas regulamentadoras sobre pesquisas que envolvem seres humanos do Conselho Nacional de Saúde. Ministério da Saúde. Resolução n. ${ }^{\circ}$ 196, de 10 de Outubro de 1996.

Como procedimento ético foi pedido autorização ao presidente da AHI e a coordenadora do curso de enfermagem da URCA para realização da coleta de dados. Sendo que também foram requeridas, as mulheres que concordaram em participar do estudo, explicações detalhadas sobre a finalidade e os objetivos da pesquisa, assinando o termo de consentimento livre e esclarecido. A partir daí as entrevistadas, voluntariamente teve a oportunidade de aceitar ou não em participar do estudo referido.

O projeto foi enviado ao Comitê de Ética em Pesquisa (CEP) da Universidade Regional do Cariri, localizada na cidade de Crato-CE, cujo CAAE: 0058.0.450.000-11, aprovado com o $\mathrm{n}^{\mathrm{o}}$ de protocolo 035/2011.

\section{Resultados e Discussão}

Participaram do estudo 12 mulheres na faixa etária de 19 á 32 anos de idade, residentes em diferentes bairros do município de Iguatu-ce, e que afirmam fazer parte da classe homoafetiva.

Dentre as entrevistadas percebe-se que a faixa etária predominante entre as mulheres é de 19 á 22 anos de idade, com 50\% das entrevistadas. Sendo assim, entende-se que a homoafetividade está sendo descoberta cada vez mais cedo e está acontecendo uma melhor aceitação da opção sexual entre essas mulheres.

Estas mulheres que se destacaram nesta faixa etária $(19$ - 22), vivenciam uma época moderna em que vivem novas experiências sexuais, o que se tornou cada vez mais normal entre os mais jovens, pois este permanece sendo um momento de descobertas e experiências novas. É importante destacar que de acordo com a literatura a sociedade no passado acabava recriminando as mulheres, fazendo com que elas ficassem inibidas em manifestar sua opção sexual.

Quando as mulheres descobrem suas verdadeiras orientações sexuais as reações são diversas. Ocorre, por parte de algumas, uma mudança de vida responsável pelo abandono de todo o passado amoroso à consequiente experiência de viver um novo amor (homossexual). Outras levam uma vida 
paralela, quer dizer, mantendo as aparências para a sociedade e, ao mesmo tempo, assumindo um amor homossexual às escondidas. Por fim, há aquelas que não têm coragem de ir de encontro aos valores tradicionais e se mantêm em um relacionamento frustrado, vivendo um amor homossexual platônico, sem manter nenhuma atividade sexual prazerosa, sempre se aproximando da pessoa amada, sem revelar os seus sentimentos (OLIVEIRA, 2003).

Para os dados revelados a respeito do nível educacional das entrevistadas, constatou-se que a maioria delas possui ensino médio completo, perfazendo $42 \%$ das mulheres que responderam as perguntas do respectivo estudo.

De acordo com a pesquisa a maioria das mulheres homoafetivas, tem conhecimento da importância da educação. Destarte, adquirir pelo menos uma formação básica é necessária para se ter um bom emprego, entrar em uma universidade, ou então passar em um concurso. Logo a educação também fornece subsídios para ter uma maior produtividade no emprego e desenvolve o preparo da pessoa para encarar grandes desafios profissionais.

Portanto estudar é importante para obter conhecimento, cultura e muitos outros aspectos que se leva para a vida inteira. E ao se tratar dos preconceitos vivenciados pela classe de mulheres homoafetivas, torna-se mais necessário ainda que estes indivíduos tenham consigo um bom nível de escolaridade, como foi observado nos resultados do estudo.

Em relação à renda familiar, classificamos com base no valor do salário mínimo atual, (R\$ $545,00)$. Constatou-se que grande parcela das entrevistadas, $58 \%$ possuía uma renda referente de 2 (dois) salários mínimos. Assim o perfil da população em estudo é composto por mulheres pertencentes aos extratos socioeconômicos médios e com média escolaridade.

A sociedade tende a condenar e impõe um comportamento heterossexual na visão feminina, assim elas se sentem assustadas e pressionadas por todos, enquanto por outro lado, abala a sua consciência homoafetiva, mostrando que, para ser feliz, é preciso libertar seus sentimentos e desejos. Sendo assim muitas das mulheres só descobrem ou assumem a homoafetividade depois de adulta, quando independentes financeiramente (BRANDÃO, 2004).

Uma vez que, elas eram e continuam sendo muito discriminadas no ambiente profissional, apesar de estarem presentes em quase todas as áreas de trabalho. É fato de que os homoafetivos estão se inserindo cada vez mais no mercado de trabalho, mas para que isto deixe de ser um problema é necessário uma mudança social e cultural (BAUMGARDT, 2010).

Quanto à profissão que elas exercem, observou-se que todas tinham uma ocupação no momento, sendo que $25 \%$ são estudantes, e as restantes distribuídas em profissões diversas, como, secretária, recepcionista, gerente, operadora de caixa, garçonete e professora; mostrando que as mulheres têm aumentado seu espaço no mercado de trabalho. 
Segundo Rodrigues (2009), foi criada no ano de 1948 a Declaração Universal dos Direitos do Homem aonde vem sendo refletida por todo o mundo, motivando o debate concernente a democracia, que pode ser compreendida como o regime político destinado a proteger e promover os direitos humanos. Esse estado democrático de direito, influenciou o constitucionalismo contemporâneo visando à constatação do direito do cidadão em participar das práticas estatais, de forma igualitária.

Assim todos merecem o direito de trabalhar em um ambiente que promova oportunidades iguais de emprego, proibindo qualquer tipo de discriminação ou abuso e devem ser tratados com respeito e dignidade.

Os homoafetivos são indivíduos capacitados para trabalhar, aprender e ensinar, não havendo quaisquer riscos intransponíveis no exercício de suas funções. Busca estabelecer e garantir a todos os indivíduos, independentemente de sua orientação sexual, a formação de profissionais com identidade e respeito próprios, direitos esses inerentes a todo ser humano (BAUMGARDT, 2010).

As entrevistadas foram indagadas se tem enfrentado algum tipo de dificuldade na assistência de enfermagem na unidade de saúde, tendo como maioria das respostas, que nunca procurou o atendimento a unidade, sendo que $17 \%$ das entrevistadas afirmam que enfrenta ou tem enfrentado dificuldade na assistência.

Não, pois nunca precisei da assistência mais acho que se eu vim a precisar não vai
existir nenhum problema no atendimento. (sujeito 4)

Não, sempre que precisei fui bem recebida. (sujeito 7)

Sim, por ter opção sexual diferenciada à sociedade em geral vem a nos discriminar olhando-nos com preconceito, fazendo com que diminui a nossa procura da assistência de enfermagem. (sujeito 8)

A ida a consulta na unidade de saúde para realização de exames femininos pode ser compreendida como uma afirmação de necessidades femininas, e, portanto, uma conduta para as mulheres lésbicas que se percebem como femininas. Para as mulheres que possuem atributos e posturas corporais "masculinizadas", a consulta adquiriu um significado de explicitar os trejeitos desviantes, que somado às representações de que o envolvimento lésbico não oferece riscos nem requer ações específicas com a saúde, tornam a busca por cuidados ginecológico especialmente complexo e difícil (RODRIGUES, 2010).

Enfrentar a complexidade dos determinantes sociais da vida e da saúde das pessoas e coletividades requer intervir sobre a exclusão social, mas requer também o reconhecimento dos fatores que se entrecruzam, maximizando a vulnerabilidade e o sofrimento de grupos específicos. Deste modo para que uma população tenha saúde, é necessário que todos articulem gerando uma interferência 
eficaz sobre os determinantes sociais da saúde para assim obter mudanças na qualidade de vida e no nível de saúde da população (SILVA, 2009).

Entende-se assim a humanização como um ponto essencial na assistência que tem como objetivo resgatar as relações com as pessoas, com as técnicas, com o ambiente ou os locais onde ocorrem as assistências, diminuindo as dificuldades encontradas pelos profissionais na assistência humanizada.

Consideram-se as discriminações e homofobia na assistência à saúde, como situações produtoras de preconceitos e sofrimento. É preciso compreender que a homofobia não ocorre de maneira isolada de outras formas de discriminação social, ela caminha ao lado e se reforça pelo machismo, o racismo, a misoginia e todas as formas correlatas de discriminação (BRASIL, 2008).

Assim humanização na atenção á saúde do usuário e do cuidador precisa ser realizada, de forma que considere cada pessoa como ser único, devendo ser aceito com suas necessidades e expectativas particulares inter-relacionadas, para zelar pela saúde na sociedade.

Quando indagadas sobre o preparo do enfermeiro para lidar com o grupo de mulheres homoafetivas existiu uma divisão de opinião sendo que 58\% das entrevistadas acreditam que os enfermeiros ainda não estão preparados humanamente para lidar com a homoafetividade feminina. Conforme as falas que segue:

Não, pois há pouco interesse dos profissionais em relação o saber da opção sexual durante o atendimento tratando todas as mulheres como heterossexual. (sujeito 6)

Não, pois ainda existe uma grande barreira entre profissionais e nós pacientes homossexuais, que deve ser quebradas por eles, impedindo assim que aconteça um vínculo de confiança para assim a consulta aconteça de forma correta para as orientações para agente (sujeito 4)

Alguns estão, pois tem outros que tem muito preconceito e apesar de não querer demonstrar acaba repassando uma impressão negativa para agente durante a consulta (sujeito 2)

Pelos discursos podemos perceber o quanto as mulheres estão insatisfeitas com relação à forma como são atendidos pelos profissionais, ressaltando que estes deveriam ter mais preparo para atender esse público, para assim poder diminuir a barreira existente na consulta destas pacientes.

A proposição de políticas de saúde para grupos específicos gera polêmica por ser a princípio, contraria a universalidade preconizada constitucionalmente aos direitos sociais, dentre os quais o direito à saúde.

Sendo o enfermeiro um profissional que trabalha com pessoas e que têm como preocupação a melhoria da qualidade de suas vidas, é necessário haver uma abordagem adequada diante de seus clientes, a fim de que possam atingi-las em sua plenitude, sendo de fundamental importância a busca 
criativa de novas alternativas para assistência, associando saúde e educação das populações, num intercâmbio constante entre o saber desenvolvido no viver diário e o oriundo na vida profissional, inseridos em um contexto histórico, político, social, econômico e cultural (BUDÓ, 2004).

Assim, o processo de enfermagem apresenta-se baseado em princípios e regras que são conhecidos por promover cuidado de enfermagem eficiente, definido como dinâmica das ações sistematizadas e inter-relacionadas, visando à assistência ao ser humano. Nem todos os enfermeiros aplicam uma assistência sistematizada, limitando-se em habilidades técnicas, o que faz deixar de levantar os problemas de enfermagem do cliente e de planejar os cuidados, ficando a assistência, neste caso, limitada a ações isoladas no decorrer de suas atividades.

É necessário para uma boa assistência, que aconteça relacionamento interpessoal enfermeiropaciente, porém sabe-se que podem surgir fatos imprevistos que podem ou não serem constrangedores para ambos, como o sentimento de repulsa, por parte dos profissionais, ao terem que assistir um cliente homoafetivo. Embora sejam profissionais, são também seres sexuados dotados de bagagem cultural, sentimentos e preconceitos (GALANTE, 2001).

Assim, como forma de melhorar o atendimento abrangendo todos os tipos de públicos, a assistência de enfermagem deveria fazer uso da aplicação do processo de enfermagem, pois proporciona ao enfermeiro a possibilidade da prestação de cuidados individualizados, centrada nas necessidades humanas básicas.

A saúde, enquanto direito de todos e dever do Estado, é, no entanto, um ideal a conseguir, sendo a realidade brasileira atravessada por iniqüidades que devem ser combatidas com ações que proponham reverter quadros de exclusão e da violação de direitos humanos fundamentais, na perspectiva da promoção da eqüidade para distintos grupos sociais (LIONÇO, 2008).

De acordo com as entrevistadas a educação em saúde não vem sendo trabalhada de forma correta, 71\% afirma que a educação é feita pelos profissionais visando à mulher como ser heterossexual, esquecendo de indagar a opção sexual das mesmas para assim serem feitas as orientações corretas.

Não, nunca vi ser feita relacionado diretamente a nós. (sujeito 3)

Não, acho que deveria ser perguntado primeiro o tipo de opção sexual, para assim ser feito a educação. (sujeito 11)

Não, existem muitas campanhas que estimula muito à prevenção e promoção a saúde, porém vendo a homossexualidade como homens gays e abordando pouco em relação à mulher. (sujeito 7) 
Entende-se que a educação em saúde se sobrepõe o conceito de promoção da saúde, como uma definição mais ampla de um processo que abrange a participação de toda a população no contexto de sua vida cotidiana, e não apenas das pessoas sob risco de adoecer.

Assim, a importância da interdisciplinaridade dos diferentes saberes, da solidariedade entre pesquisadores e ativistas e da integralidade das ações de prevenção e assistência, são de especial valor para que se desenvolva uma educação em saúde que não deixe subentendida ou mesmo excluída a classe de mulheres homoafetivas.

O MS passou a recomendar o aconselhamento na rotina dos serviços, a partir da mudança no perfil epidemiológico da AIDS, que passou a acometer cada vez mais mulheres em idade reprodutiva, enfatizando a necessidade de incluir trabalhos de prevenção contra as DST/HIV na rotina dos serviços de assistência à saúde da mulher. Diante disso a abordagem deve estar voltada às necessidades de cada paciente de acordo com a sua orientação sexual, envolvendo temas relacionados aos aspectos sociais e comportamentais de mulheres homoafetivas, bem como garantir a qualidade do atendimento a essa população. Entretanto, percebe-se uma dificuldade dos profissionais para abordar esses temas, sendo necessária a capacitação e educação permanente dos mesmos (BRASIL, 2003).

O profissional deve estar habilitado para escutar e estar aberto às demandas de mulheres, para que assim o aconselhamento aconteça de forma correta. O desempenho destas atividades implica em uma readequação dos serviços e preparo dos profissionais especialmente em temas relacionados à abordagem da sexualidade.

O aconselhamento deve incorporar os componentes de orientação/informação, avaliação de riscos e apoio emocional. A avaliação dos riscos pessoais para se contrair DST's envolve a abordagem de temas delicados para a maioria dos profissionais, como o exercício da sexualidade, número de parceiros sexuais, práticas sexuais, uso de drogas especialmente intravenosas, entre outros. Ocorre que, em virtude da dificuldade da abordagem desses temas, os profissionais de saúde não reconhecem a avaliação de riscos como um dos componentes importantes do aconselhamento, o que pode estar comprometendo esta prática nos serviços (MIRANDA, VASCONCELOS, BARROSOS, 2003).

De acordo com Terto (2002), a atenção na saúde de grupos sociais é importante incluir a noção de tratamento, a noção de cuidado, que amplia o foco para além de tratar sintomas, mas considerar também a trajetória e os projetos de vida dos indivíduos. O tratamento seria, assim, uma forma de contribuir não apenas para a supressão dos sintomas clínicos, mas também para o desenvolvimento de projetos de vida, de estímulo à inserção social e de realização pessoal.

Não existe o conhecimento das mulheres de nenhuma atividade realizada em conjunto com grupo de homoafetivo feminino, sabe-se somente da existência da parada gay que se resume em um evento que acontece uma vez por ano e consiste na reunião dos grupos de GLBT. Isso é expresso nas falas: 
Não, somente a parada gay que acontece uma vez por ano onde acontece o encontro de toda classe homossexual. (sujeito 12)

Não, nunca fui chamada para nenhum evento. (sujeito 5)

$\mathrm{Na}$ literatura não foi encontrada nenhuma atividade voltada somente para as mulheres homoafetivas, pois engloba todo grupo GLBT como um ser único e isolado.

O MS vem envolvendo-se na promoção de maior eqüidade em saúde de todos os grupos populacionais vulneráveis do país. A expectativa é que o grupo GLBT deverá ter em conta, a efetividade do acolhimento das necessidades de saúde desta população, em contrapartida, da inserção vigorosa dos movimentos sociais GLBT na defesa do SUS. Assim, é indispensável à ampliação da participação desse contingente da sociedade nos espaços participativos formais e alternativos já existentes e naqueles que poderão e deverão ser criados (BRASIL, 2008).

Desta forma via-se uma necessidade especial para o grupo no amplo da saúde, assim em maio de 2011 o Governo Federal lançou o Plano Nacional de Promoção da Cidadania e Direitos Humanos de LGBT, essa iniciativa foi promovida Pela Secretaria Especial de Direitos Humanos, realizado no dia internacional contra a homofobia onde foi comemorado em todos os estados brasileiros, representados por 44 cidades, promoverão atividades para homoxessuais e manifestações contra a homofobia. Como o objetivo de relembrar que a homossexualidade não é doença e tendo uma característica de protesto e de denúncia (BRASIL, 2011).

As participantes do estudo sugeriram que fossem realizados mais treinamentos específicos para os profissionais saberem lidar melhor com o grupo em estudo durante a assistência, para assim melhorar a prevenção de doenças e promoção da saúde dessas mulheres focando principalmente no aspecto homoafetividade.

Treinamento específicos de humanização e igualdade para os profissionais, para assim ser feito um melhor atendimento durante a consulta. (sujeito 9)

Realização de atividades para melhora do atendimento na assistência e acabar com qualquer tipo de descriminação. (sujeitol)

Algum movimento que seja com os profissionais e o grupo para assim todos se conhecerem melhor para acabar com qualquer tipo de preconceito. (sujeito 7)

Visando ao bom funcionamento do sistema de saúde brasileiro buscam-se estratégias que possibilitem o aprimoramento do contato humano entre profissionais de saúde e os usuários. Visto que como foi observado nas falas das mulheres, a grande maioria sente a necessidade de um contato mais humanístico e com igualdade entre os profissionais e a clientela, como também atividades que 
envolvam o grupo, ou seja, de forma coletiva, para que se acabe com a discriminação vivenciada até mesmo entre elas.

Ao se tentar tornar um atendimento humanístico, deve-se adaptar o conhecimento formal empírico complementando com os aspectos tecnológicos, científicos e sociais, tendo em vista uma assistência personalizada, respeitando as características físicas, morais e sociais do paciente, objetivando um contato mais próximo, menos mecanicista com o paciente (FELL, 2010).

Desta maneira no ano 2000 o MS implantou, o Programa Nacional de Humanização da Assistência Hospitalar e, posteriormente, a Política Nacional de Humanização, visando atender às demandas subjetivas manifestadas pelos usuários e trabalhadores dos serviços de saúde, baseando-se na integralidade da assistência, tentando melhorar assim a humanização no atendimento a partir do amparo dos princípios predeterminados como: a integralidade da assistência, a eqüidade e o envolvimento do usuário, além de favorecer a criação de espaços que valorizem a dignidade do profissional e do paciente (AMESTOY, SCHWARTZ, THOFEHRN, 2006).

Apesar da criação de uma política de humanização, via a necessidade de uma política de saúde para população homoafetiva, deste modo no ano de 2004 foi evidenciada e formalizada o Brasil sem Homofobia - Programa de Combate à Violência e à Discriminação contra GLTB e de Promoção da Cidadania Homossexual - Conselho Nacional de Combate à Discriminação (BRASIL, 2004b).

Esse programa situa no centro das políticas públicas para a população em questão o combate ao preconceito e às intolerâncias, que têm como consequiência iniqüidades e falta de garantia de direitos fundamentais a GLBT.

Com ampla participação da sociedade civil, ainda instituiu-se em 2004 o Comitê Técnico de Saúde da População GLTB no âmbito do MS onde a principal atribuição desse comitê é justamente sistematizar proposta de política nacional da saúde da população GLBT, com vista a garantir a eqüidade na atenção à saúde também para esses segmentos populacionais (LIONÇO, 2008).

Com base nos discursos apresentados é certo afirmar que enquanto algumas mulheres passam por situações de insatisfação, outras nem chegam a procurar atendimento. Como foi visto muitas mulheres queixou-se da despreparação dos profissionais, isso nos faz refletir que por parte delas não haveria resistência a procurar atendimento de saúde caso os profissionais a recebessem de forma mais preparados.

Assim, ao se planejar ações educativas para o estabelecimento de uma consulta satisfatória, é preciso analisar a existência de um conjunto de interações, entre estas, o conhecimento do ambiente em que elas se encontram inseridas. Essa atitude possibilita ao profissional exercer estratégias individualizadas, direcionada à sua realidade, facilitando o atendimento e satisfazendo a clientela.

No entanto, acreditamos também que independente da influência exercida pelos profissionais de saúde, as reflexões acerca do preconceito sobre mulheres homoafetivas, devem também partir das 
mesmas através da interpretação do seu pensar, de sua fala, da busca de informações mais concisas e do seu fazer sobre os cuidados com sua saúde. Isso possibilita a construção de modelos mais condizentes e a desconstrução de conceitos e valores errôneos que venham a interromper a prática dos cuidados para com a saúde desta clientela.

\section{Considerações Finais}

A homoafetividade feminina através das lutas sociais junto ao grupo GLBT vem conquistando aos poucos o seu espaço diante a sociedade, o movimento social adquiriu visibilidade na sociedade a partir do enfrentamento da violência decorrente da homofobia caracterizada como violação de direitos humanos, da mobilização pela igualdade de direitos e pelo direito à diferença.

As mulheres homoafetivas estão cada vez mais cedo assumindo sua opção sexual diante a sociedade, tendo como conhecimento a importância do estudo, independentemente qual profissão venha á exercer, muitas delas assume sua homoafetividade logo após a sua conquista da independência financeira sentido assim preparadas para tomar suas próprias decisões diante á sociedade. Nesse contexto, a construção da Política Nacional de Saúde Integral está fundamentada nas evidências de preconceitos e discriminações que violam direitos humanos desses grupos populacionais, expressando assim o compromisso da sociedade com a garantia do direito à saúde sem qualquer preconceito e discriminação.

Para que a assistência na unidade de saúde seja trabalhada de forma correta se faz necessário não somente a diminuição da discriminação, mas também o entendimento e conhecimento da visão das mulheres enquanto homoafetivas em relação à assistência de enfermagem, pois entende que a importância da assistência na saúde da mulher principalmente as homoafetivas que procuram bem menos a assistência do que as heterossexuais, acreditando assim estão livres de doenças recorrentes.

Dessa maneira é importante a busca ativa dessas mulheres e o melhor esclarecimento da necessidade das mesmas, para que elas procurem a assistência para ser trabalhada a sua saúde de acordo com as suas necessidades.

O enfermeiro deve está preparado humanamente e tecnicamente para lidar com o grupo, porém as entrevistadas acreditam que isto esta longe de acontecer, isto pode ocorrer não por os enfermeiros está despreparados, mais por elas se sentirem excluídas diante da sociedade, e tendendo assim a ver também o profissional como um ser descriminante.

Acredita-se assim que a educação em saúde não vem sendo trabalhado de forma correta, visando à mulher como ser heterossexual deixando a desejar na orientação e nos cuidados. Desta maneira as mulheres sentem a falta de uma atividade exclusiva voltada para o grupo. 
Conhecer a opção sexual individual do paciente se torna de importância absoluta diante da assistência fazendo de suma necessidade a indagação da mesma para que assim seja feito o atendimento de forma individual e correta. A enfermagem sendo o gerenciador da equipe tendo como responsabilidade a quebra das barreiras existenciais de preconceitos com o paciente e a equipe, fazendo necessário desta maneira um vínculo entre profissionais e pacientes tentando tornar a assistência eficaz e derrubando de uma só vez a homofobia diante do paciente.

\section{Referências}

ARAÚJO, M. A. L. GALVÃO, M. T. G. SARAIVA, M. M. M. ALBUQUERQUE, A. D. Relação usuária-profissional de saúde: experiência de uma mulher homossexual em uma unidade de saúde de referência de fortaleza. Escola Anna Nery, Rio de Janeiro, vol.10, n.2, p. 323-327, ago. 2006.

AMESTOY, S. C. SCHWARTZ, E. THOFEHRN, M. B. A humanização do trabalho para os profissionais de enfermagem, Revista eletrônica Acta Paulista de Enfermagem, vol.19, n.4, São Paulo, out/dez 2006.

BARDIN, L. Análise de conteúdo. Lisboa: Edições 70, 2008.

BAUMGARDT, D. Os homossexuais e o preconceito no mercado de trabalho frente aos princípios constitucionais, Revista Eletrônica Âmbito Jurídico, Rio Grande do Sul, p. 74, mar. 2010.

BRANDÃO, A. M. "Ser e Saber" - (re) visitações do passado e construção das identidades (homos)sexuais, Associação Portuguesa de Sociologia (APS) Congresso Português de Sociologia, Portugal - Lisboa, 2004.

BRASIL, Ministério da Saúde. Políticas e diretrizes de prevenção das DST/AIDS entre mulheres. Brasília, DF, mar. 2003.

. Ministério da Saúde. Política Nacional de Atenção Integral à Saúde da Mulher. Brasília, 2004a. 
Ministério da Saúde. Brasil sem Homofobia: Programa de Combate à Violência e à

Discriminação Contra GLTB e Promoção da Cidadania Homossexual. Conselho Nacional de Combate à Discriminação. Brasília, DF: Ministério da Saúde, 2004b.

. Ministério da Saúde. Departamento de Apoio à Gestão Participativa, Secretaria de Gestão Estratégica e Participativa. Saúde da população de gays, lésbicas, bissexuais, travestis e transexuais. Revista eletrônica Saúde Pública, vol.42, n.3, 2008.

. Ministério da Saúde. Secretaria Especial dos Direitos Humanos, Brasília, DF, Ministério da Saúde, maio de 2011. Disponivel em: <portal.mj.gov.br/sedh/homofobia/planolgbt.pdf >. Acesso em: 21 de jun 2011.

BUDÓ, M. L. D. Saupe, R. Conhecimentos Populares E Educação Em Saúde Na Formação Do Enfermeiro, Revista Brasileira de Enfermagem, Brasília, vol. 2, n. 57, p.165-169, mar/abr 2004.

FELL, A. MATTÉ, F. C. CAMPO, G. B. Humanização da Assistência de Enfermagem á Pacientes Atendidos na Emergência em um Hospital de Pequeno Porte no Município de Xaxim - SC, Chapecó-SC, jun. 2010.

GALANTE, A. C. O profissional de enfermagem perante uma questão de sexualidade, Revista do Centro Universitário Barão de Mauá, v.1, n.2, jul/dez. 2001.

LIONÇO, T. Que Direito à Saúde para a População GLBT? Considerando Direitos Humanos, Sexuais e Reprodutivos em Busca da Integralidade e da Eqüidade. Revista de Saúde e sociedade, São Paulo, vol.17, n.2, p. 11-21, 2008.

MIRANDA, K.C.L. VASCONCELOS K.S. BARROSOS M.G.T. Aconselhamento em HIV/AIDS: um conceito a partir dos profissionais, Escola Anna Nery Revista de Enfermagem, ago. 2003.

OLIVEIRA, E. M. BARBOSA, M. R. ANÍBAL, A. M. V. M. KOSSEL, K. V. MORELLI, K. BOTELHO, L. F. F. STOIANOV, M. Atendimento às Mulheres Vítimas de Violência Sexual: Um Estudo Qualitativo. Revista de Saúde Pública, São Paulo, vol. 39, n. 3, p. 376-382, jun. 2005.

RODRIGUES, J. M. Ser mulher e homossexual: Um direito de ser diferente, Curso de Direito da Universidade de Salvador (UNIFACS), n. 112, 2009. 
RODRIGUES, J. L. Schor, N. Saúde Sexual e Reprodutiva de Mulheres Lésbicas e Bissexuais, Seminário Internacional Fazendo Gênero, Universidade Federal de Santa Catarina, Ed. 9, ago 2010.

SILVA, K. L. Promoção Da Saúde Em Espaços Sociais Da Vida Cotidiana, Escola de Enfermagem da UFMG, Belo Horizonte - MG, 2009.

TERTO, V. J. Homossexualidade e saúde: desafios para a terceira década de epidemia de HIV/AIDS, Revista Brasileira Horizontes Antropológicos, vol. 8, n.17, p. 147-158, Porto Alegre, jun, 2002.

Como citar este artigo (Formato ISO):

TEODORO, I.P.P.; FELIPE, N.K.S.; TEODORO, L.P.P. A Percepção das mulheres homoafetivas frente a assistência de enfermagem na saúde da mulher. Id on Line Revista de Psicologia, Fevereiro de 2014, vol.8, n.22, p. 130-144. ISSN 1981-1189.

Recebido: 10/12/2013

Aceito: 05/02/2014 